\title{
BMJ Open Social Autopsy of maternal, neonatal deaths and stillbirths in rural Bangladesh: qualitative exploration of its effect and community acceptance
}

\author{
Animesh Biswas, ${ }^{1,2}$ Fazlur Rahman, ${ }^{2}$ Charli Eriksson, ${ }^{1}$ Abdul Halim, ${ }^{2}$ \\ Koustuv Dalal ${ }^{1}$
}

To cite: Biswas A, Rahman $F$, Eriksson $\mathrm{C}$, et al. Social Autopsy of maternal, neonatal deaths and stillbirths in rural Bangladesh: qualitative exploration of its effect and community acceptance. BMJ Open 2016;6:e010490. doi:10.1136/bmjopen-2015010490

- Prepublication history for this paper is available online. To view these files please visit the journal online (http://dx.doi.org/10.1136/ bmjopen-2015-010490).

Received 13 November 2015 Revised 14 June 2016 Accepted 29 July 2016

CrossMark

\footnotetext{
${ }^{1}$ Department of Public Health Science, School of Health and Medical Sciences, Örebro University, Örebro, Sweden ${ }^{2}$ Centre for Injury Prevention and Research, Dhaka, Bangladesh
}

Correspondence to Dr Animesh Biswas; ani72001@gmail.com

\section{ABSTRACT}

Objectives: Social Autopsy (SA) is an innovative strategy where a trained facilitator leads community groups through a structured, standardised analysis of the physical, environmental, cultural and social factors contributing to a serious, non-fatal health event or death. The discussion stimulated by the formal process of SA determines the causes and suggests preventative measures that are appropriate and achievable in the community. Here we explored individual experiences of SA, including acceptance and participant learning, and its effect on rural communities in Bangladesh. The present study had explored the experiences gained while undertaking SA of maternal and neonatal deaths and stillbirths in rural Bangladesh.

Design: Qualitative assessment of documents, observations, focus group discussions, group discussions and in-depth interviews by content and thematic analyses.

Results: Each community's maternal and neonatal death was a unique, sad story. SA undertaken by government field-level health workers were well accepted by rural communities. SA had the capability to explore the social reasons behind the medical cause of the death without apportioning blame to any individual or group. SA was a useful instrument to raise awareness and encourage community responses to errors within the society that contributed to the death. People participating in SA showed commitment to future preventative measures and devised their own solutions for the future prevention of maternal and neonatal deaths.

Conclusions: SA highlights societal errors and promotes discussion around maternal or newborn death. SA is an effective means to deliver important preventative messages and to sensitise the community to death issues. Importantly, the community itself is enabled to devise future strategies to avert future maternal and neonatal deaths in Bangladesh.

\section{INTRODUCTION}

Bangladesh is expected to achieve Millennium Developmental Goals 4 and 5 by the end of 2015. Significant progress has

\section{Strengths and limitations of this study}

- The different methods used in this qualitative study (focus group discussions, in-depth interviews, direct observation) were useful to triangulate different results to deeper understanding of the intervention.

- Participant observation allowed direct observation of the process of Social Autopsy and community interactions.

- The study relied on self-reporting alone.

- No quantitative methodologies were employed.

been made in reducing maternal and neonatal deaths. ${ }^{1}$ However, many ingrained social factors and delays still contribute to maternal and newborn mortality in Bangladesh. ${ }^{2}{ }^{3}$ Recent studies in 2014 have shown that the maternal mortality ratio (MMR) has reduced to 170 per 100000 live births and newborn death to 23/1000 live births. ${ }^{45}$ To maintain or further reduce mortality, it is essential that the death-specific social factors, errors and barriers that contribute to maternal and infant deaths in Bangladesh are fully understood so that positive responses at the local level can be implemented to prevent future deaths in the community.

Maternal death review findings in Bangladesh have shown that $35.2 \%$ of deaths occur at home in rural communities. ${ }^{6}$ Verbal autopsies have been used in many cases to explore the cause of death with deceased family members. Verbal autopsies focused on the signs, symptoms and circumstances that caused the death. ${ }^{7}$ Verbal autopsies have been used in many developing countries to explore causes of maternal and neonatal deaths. $^{8-18}$ In Bangladesh, maternal death review findings play a key role in providing proper feedback on deaths. ${ }^{6}$ However, using 
the verbal autopsy method, it is not possible to determine non-biological contributory factors. An additional autopsy-herein called Social Autopsy (SA)—is useful because it has the ability to explore social, behavioural and health system determinants of maternal and neonatal death. ${ }^{19}$ Bangladesh has experience in Maternal and Neonatal Death Reviews (MNDRs) system in the low income country context. MDNRs support the examination of each maternal and neonatal death in the community by performing 'verbal autopsies', which are used to understand the medical causes and contributing factors relating to maternal and neonatal deaths. ${ }^{20-22}$ Within the MNDR system, the government has also initiated $\mathrm{SA}$ as a social intervention.

In Bangladesh, maternal and neonatal death SA is used to discuss specific deaths notified by field-level health staff, which is then relayed to a focal point at Upazila health complexes (UHCs; primary healthcare centres). Following death notification, front-line health and family planning field supervisors perform verbal autopsies to understand the medical causes and complications relating to the death. Thereafter, the same staff perform SAs on a subsequent day to discuss the death with the deceased's neighbours to explore the social causes and errors behind the deaths. ${ }^{21}$ This tends to elicit community solutions and responses on how to act in the future to reduce complications for the mother and her newborn. ${ }^{23}$ Here we explored individual experiences of SA, including acceptance and participant learning, and its effect on rural communities in Bangladesh. The present study had explored the experiences gained while undertaking SA of maternal and neonatal deaths and stillbirths in rural Bangladesh.

\section{METHODS}

The study was performed in the Thakurgaon and Jamalpur districts of Bangladesh. In 2010, MNDRs were piloted in Thakurgaon district by the Directorate General of Health Services (DGHS) and Directorate General of Family Planning (DGFP). In 2011, MNDRs were expanded to another three (follow on) districts: Moulvibazar, Narail and Jamalpur. In this study, Thakurgaon and Jamalpur were selected. Jamalpur district was randomly selected by lottery from the three follow-on districts, rather than considering all the three districts due to time and fund constraints. Thakurgaon is situated $450 \mathrm{~km}$ from Dhaka in the northern part of the country and has a population of $\sim 1.4$ million, while Jamalpur is about $140 \mathrm{~km}$ north of Dhaka and has a population of $\sim 2$ million.

The DGHS and DGFP agreed and approved the pilot SA in Thakurgaon and subsequently approved scale-up to other districts. A supervisory and monitoring mechanism was established at the national and district level to supervise and monitor its utilisation in maternal and neonatal deaths. First-line supervision was carried out at the community level by Health Inspectors (HIs),
Assistant Health Inspectors (AHIs) from the Health Department and Family Planning Inspectors (FPIs) from the Family Planning Department. Each inspector was assigned to conduct SAs on maternal and neonatal deaths and stillbirths. The SA process included community discussion on death issues and interaction between individuals in the community and health workers to explore social errors and factors contributing to death.

We conducted a qualitative study with data collected at two time points. Different data collection techniques were used: focus group discussions (FGDs), group discussions (GDs), in-depth interviews (IDIs), participant observations and also review of documents related to SA development. The SA process and its acceptance were assessed at the end of initial piloting in January 2011 in Thakurgaon. We have looked at how the health system has accepted SA in the community and how the community people participated in the SA session and their acceptance.

Effects of SA was explored from both the study districts in October 2011, where it was explicated how SA had been used by the community people and health system for the improvement of their maternal and neonatal health in both districts.

The MNDR system covered notification of all maternal and neonatal deaths and stillbirths in the community and health facilities and were reported to MNDR focal points at the UHCs. ${ }^{20}{ }^{21}$ A verbal autopsy was then performed on death in each community by the government field-level health workers (HIs and FPIs) assigned by the Upazila focal point at the UHC. Field-level health staff completed the verbal autopsy in the community using a structured questionnaire before returning it to the focal point. ${ }^{21}$ In addition to evaluating the social factors, barriers and causes related to each death, the Upazila focal point assigned the same health worker to conduct an SA at a later date with neighbours of the deceased's household. Field-level health workers received 1 day training on how to facilitate an SA session at the field. The health worker visited the community where the maternal or neonatal death or stillbirth occurred, conducted the SA, and returned the report to the MNDR Upazila focal point (figure 1).

\section{Acceptance data collection}

To obtain qualitative information on SA and its acceptance, we randomly selected three Upazilas from Thakurgaon. Three FGDs were conducted with healthcare providers including HIs, AHIs and FPIs, one in each Upazila. In each of the FGDs, there were group of 7-9 members. Only two female health workers participated in the FGDs, because in the health system, field-level health and family supervisors are mostly male.

A total number of 18 IDIs were conducted. Among the 12 randomly chosen communities, SA participants selected included adolescents, reproductive-age mothers, community leaders, household heads and extended family members to understand their views on SA. The 


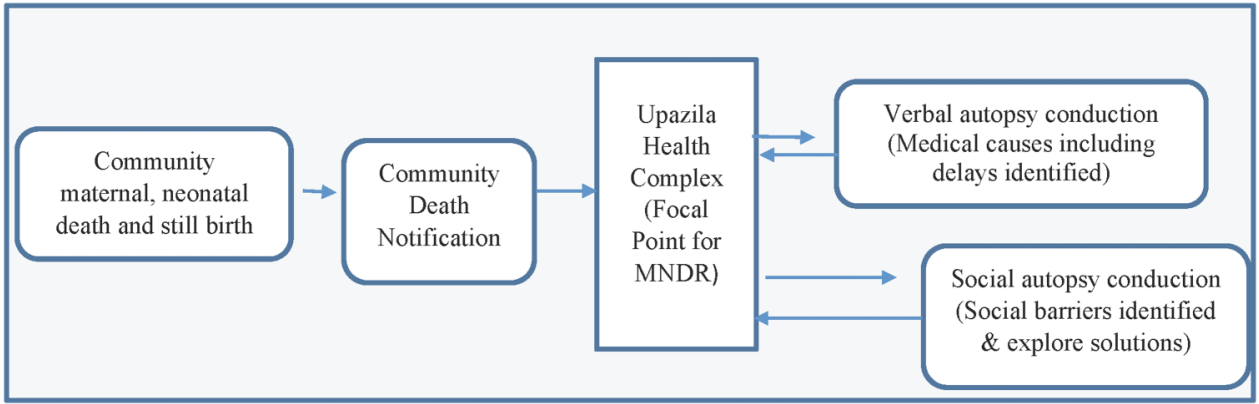

Figure 1 Social Autopsy framework. MNDR, Maternal and Neonatal Death Review.

participants were aged between 20 and 68 years. Seven of them were female participants, rest were male participants. A total of six IDIs were performed with the Upazila Health and Family Planning Officers (UHFPOs) and Upazila Family Planning Officers (UFPOs) in all three Upazilas. We also recorded participants' observations during six SA sessions, two in each Upazila. The research officers observed entire SA sessions as observers starting from gathering people in their homes until the completion of the session. Researchers followed a checklist to record key points during SA sessions (table 1 and box 1 ).

\section{Understanding the effects of SA on the community}

To understand the effect of SA on the community, Jamalpur was randomly selected from the follow-on districts for the study. Three Upazilas were chosen from each district in October 2011. A total of six FGDs were conducted with HIs, AHIs and FPIs at UHCs, where two research officers (anthropologists) collected the data. Only two health workers were female, rest of the workers were male. FGDs were participatory, and researchers used a guideline containing a number of prompts. One researcher facilitated the discussion, while the other acted as note taker and took responsibility for overall management of the discussion. Each FGD lasted around 45 min to 1 hour.

A total number of 12 IDIs were performed. Six IDIs were undertaken with the UHFPO from the Health Department and another six IDIs were performed with the UFPO from the Family Planning Department at the Upazila using a guideline. Each IDI lasted between 20 and $30 \mathrm{~min}$.
Different people who participated in the SA session were interviewed. Therefore, GD took place instead of FGD with SA participants which was conducted after an SA conducted in the community. There were 8-12 participants in each GD. It was noted that in each group there were 2-4 male participants. The age group of participants in GD varied from 19 to 65 years. During the data collection, four GDs were conducted, two in each district, using a guideline (table 2).

\section{Participant observation and document review}

The research officers observed participants during a randomly selected SA session from each of the Upazilas in Thakurgaon district. Two of them were on maternal deaths, two were on neonatal deaths and another two were on stillbirths. Investigators used a checklist and observed the entire session as observers, noting key points observed during the session. Documents related to development of SA in the MNDR system were also reviewed. Among those, meeting minutes of five meetings, one set of tools, one note of record, training guideline, manual for conduction SA training and one set of behavioural change communication (BCC) materials were seen. All types of documents help the researcher to explore the meaning, develop understanding and empirical knowledge. ${ }^{24}$ All documents were read very carefully to understand how the SA has been introduced in maternal and neonatal death.

Research officers received formal training on the guidelines, checklists and prompts used in interviews. Pretesting was performed before the final interviews, and tools were modified accordingly. Informed verbal

Table 1 Qualitative methods used in January 2011 in Thakurgaon district

\begin{tabular}{lll}
\hline Method used & Participants & Numbers \\
\hline Focus group discussion & Health Inspector & 3 (1 in each Upazila) \\
& Assistant Health Inspector & \\
In-depth interview & Family Planning Inspector & $3(1$ in each Upazila) \\
& UHFPO & $3(1$ in each Upazila) \\
& UFPO & 12 (4 in each Upazila) \\
Observation & SA participants (7 male and & 6 (2 in each Upazila) \\
\hline UFPO, Upazila Family Planning Officer; UHFPO, Upazila Health and Family Planning Officer.
\end{tabular}


Box 1 Checklist for observation

\section{Sitting arrangement of participants}

Male and female participation

Facilitator's role in Social Autopsy (SA) conduction

Interaction of community people on the issue

Exploring social barriers/errors behind the death

Decision-making for future prevention

Use of behavioural change communication materials during SA session

Presence of social leaders/stakeholders

Community responses

Acceptability of community to discuss on the issue

consent was obtained from each participant before the FGDs, IDIs and GDs. Interviews were audio recorded in addition to notes taken by the research officers. Transcripts were subsequently prepared from the audio recordings and hand notes in Bengali and then translated into English. The investigators verified the quality of $\sim 10 \%$ of transcripts to ensure every component was captured as per the objectives. Data analysis was then conducted by examining the transcripts and notes taken in detail to extract views on SA, with every component captured as per the objectives. Data were then coded line by line and categories and themes identified. Data were first superficially examined by content, then read through, and then interpreted. Content and thematic analyses were performed; content analysis is an appropriate method for text analysis and was particularly suited to document review. ${ }^{25-27}$ Careful reading of each of the documents, finally uncovered the relevant theme related to this area. ${ }^{24}$ Each theme for the different methods used in the study were carefully examined to obtain key findings under the different themes analysed.

Informed verbal consent was obtained for each interview and GD. Moreover, verbal consent (due to high proportions of illiteracy) was obtained from the community during observation session. The aims and objectives of the research and utilisation of the findings were clearly explained to each participant. Upazila and district health managers interviewed in the study formally sought time to conduct interviews. It was convenient for all participants in the interviews and GDs to take informed consent.

\section{RESULTS}

\section{Document review}

Examination of existing documents showed that SA of maternal and newborn health had not been introduced before 2010 in Bangladesh. It is, therefore, a relatively new and innovative concept for the country. No structured instruments had been taken from other countries already performing SA. Document review showed that a series of national meetings had been held to develop the guidelines, tools and implementation framework, including determining who would conduct SA in the community. The framework was also discussed at the district level before being piloted to obtain feedback from the field-level health staff on how they could conduct the work. Review findings reveal that community views have also been reviewed before finalisation of SA. BCC materials were further developed at the national level using existing BCC materials produced by national governments in other maternal and newborn health programmes. A panel of experts including government officials, technical experts, public health specialists and individuals representing gynaecology and paediatric professional bodies worked together to adapt some nationally-used tools to transfer knowledge at the community level. These tools included a new pictorial version of messages related to maternal and neonatal complications and maternal care service delivery. A total number of 10 festoons were developed and government agreed to use this in the districts. It was identified from the documents that formal training was provided to field-level health workers to conduct SA, including field demonstrations.

\section{Observations of conducting SA}

In all cases, SAs were carried out in courtyards near the homes of the deceased mother or child. On average, 30-50 people representing 20-30 families participated in each session and included seniors, household heads, reproductive-age mothers and their husbands and adolescents. The majority of SAs were conducted during the early morning (around 09:00) or the afternoon (around 16:00). In two cases where the health workers conducted the SA at noon, it was found that male participants found it difficult to participate in the sessions. The duration of the SA varied depending on the

Table 2 Qualitative methods used in October 2011 at Thakurgaon and Jamalpur district

\begin{tabular}{llll}
\hline Method used & Participants & Thakurgaon & Jamalpur \\
\hline Focus group discussion & Health Inspector & 3 (1 from each Upazila) & 3 (1 from each Upazila) \\
& $\begin{array}{l}\text { Assistant Health Inspector } \\
\text { Family Planning Inspector }\end{array}$ & 3 (1 from each Upazila) & 3 (1 from each Upazila) \\
In-depth interview & UHFPO & 3 (1 from each Upazila) & 3 (1 from each Upazila) \\
& UFPO & 2 (from 2 Upazila) & 2 (from 2 Upazila) \\
Group discussion & Social Autopsy participants &
\end{tabular}


community interaction and discussion generated with each other and the facilitator. The average duration of SA was about 1 hour. Participants were seated facing the facilitator either in a circle or scattered as preferred. Female participants usually sat at the front of the gathering. Each SA session contained at least two to three pregnant women who were actively involved in the discussion.

The health worker started the session by asking the neighbours to describe what had occurred before the death and to provide a summary of any complications that occurred. Participants who were knowledgeable about the case were encouraged to speak about what had happened. The health worker then invited the community to explore and discuss the social errors and barriers that had contributed to the death without blaming any individual, service provider or institution. The health worker listened to the community and identified social factors related to death from their statements. The health worker later used pictorial BCC material and discussed each picture to describe what action people should take when complications arise in mothers or neonates. Pictures on maternal and neonatal complications helped the participants to better understand what happened to the family. Finally, the health worker received confirmation from community members on how they would act in the future from the lessons learnt. Of note, in all cases the participants in SA sessions showed high levels of commitment, interest and motivation to prevent such deaths from happening in the future.

All SA sessions were interactive with active individual participation in the discussions. BCC materials were displayed during SAs, and health workers showed each page of the colourful pictorial flip chart while describing the pictures. Pictorial materials assisted in understanding, and people were willing to cooperate and to learn from each other. The team observed that participants discussed among themselves after completing the SA and also why these resources had not been shown to them earlier. Community reaction was observed and how they interacted in the session was noted. Participants reported that had they got this information before, they could have saved lives. Presence of the community leader or the elite made a difference in the session; it was observed that their presence made positive influence in taking corrective measures for future. The leader created supportive environment in the session and showed their social commitment in reducing death.

It was also observed in a few cases that the community had tried to blame the health system or providers. In these cases, the health worker refocused the discussion on the social issues.

\section{Acceptability of SA by health workers and the community}

The interviewed health workers reported that SA added a new dimension to their work and that they found it very interesting. They reported that SA was extremely interactive, particularly with the individuals who knew the facts leading to maternal or neonatal death. They also reported that SA allowed the community to explore their own barriers and develop solutions. SA was highly accepted at the community level since the community recognised SA was a powerful tool to promote preventative messages at the optimal time. Individuals in the community voluntarily organised the seating arrangements and assisted in promoting the gathering. The presence of local elites, leaders and household heads added to the acceptance of the event. Active participation in SA from different age groups, including decision makers in the family and adolescents, made the SA message very useful in real-life practice. SA was an eye opener to rectify the community to think in a positive way to prevent such type of complications in future.

An AHI said in an FGD:

It's my responsibility to share in detail on how to prevent such maternal and newborn deaths and create awareness about complications. SA provides a platform to share this with the village.

One FPI said:

Most people were listening to our discussion carefully and expected more discussion. It shows their immense interest and never wanting to quit.

A middle-aged woman reported that she was pregnant and now aware of complications and birth planning from the SA session, and that she would do as suggested by the health worker.

A recently married woman told us:

It's good for us, I learnt a lot. When I am pregnant, I must go to the doctor and take advice.

One male participant said:

I gave support to gather other people and told them we need to learn from this. They came for us, for our benefit.

One of the female guardians stated:

Social Autopsy to us is a new knowledge, our eyes were closed; we did not see the right things. They have come to help us to open our eyes to take right steps.

Another male participant said:

It's amazing, very easy to understand, particularly through pictures which clearly show the danger signs for the mother and newborn. We can remember it and follow if any mishaps occur in our community.

One UHFPO in an IDI mentioned:

Such an innovative approach can support our health system to prevent unexpected deaths in the future and, 
therefore, our health and family planning department identified SA as a major intervention in the community.

One of the UFPOs stated:

I have attended a number of social autopsies already, and the community felt so interested to know about the subject, I also deliver messages in those sessions.

\section{Acceptability of SA in identifying the social factors related to death}

Interactive discussion with individuals in a village where a maternal or neonatal death has occurred is important for identifying the social factors related to death. Participants at the meeting discussed and shared the actual events that took place around the time of an incident. The community identified their own errors, and SA provided scope to rectify the identified mistakes in the future. People in the community accepted discussing these social errors in the open, sharing each other's experiences, which prepared them accordingly.

One health worker mentioned during an FGD:

Neighbours of the deceased's family can mention what errors they observed. For example, they might have delayed their decision making or transferred the patient or conducted the delivery at home. These issues helped them to understand that such deaths could be prevented if the community was aware of certain factors.

One HI said:

Through SA I come to know that some of the families had their own beliefs, perceptions, and also myths about delivery and treatment. We were able to let them know that identification of those issues might prevent other deaths.

A UFPO said:

The families in many cases had a lack of knowledge and a poor understanding about maternal and newborn complications despite receiving antenatal care. The SA session helped such people to speak out.

One of the participants in an SA session mentioned:

During sharing of what causes the death, we understand our own errors, what we did wrong, and what we should do in the future.

Another old woman participating in an SA described:

We didn't know what we are discussing now, nobody told us when I was pregnant many years ago. I was determined to follow what I had in my mind. I understand now that it's wrong

\section{Effect of SA on the community}

SA can be used as a powerful mechanism and platform for sharing knowledge and the lessons learnt from a death that has occurred in the community. Gathering at the village level sensitises the community to take appropriate action in a timely manner. Participants in the SA concluded each session by identifying social errors behind a death and by also finding solutions. They made a commitment that they would not repeat the same errors in the future. Moreover, we found that the community were inspired by acquiring the knowledge and skills to deal with issues that had previously resulted in a death.

One HI in an FGD said that:

There are some husbands who asked their neighbour: my wife is like this... what I should do now? When we did SA, the solutions came from the community group about precautions and cure, and they now know what needs to be done.

One of the female respondents who had participated in a GD said:

When I become pregnant, I will try to save a little money every day for delivery purposes. I hope it will make me confident... and that I will have the confidence to go to hospital from my own savings.

A male participant in the GD said that:

If my wife becomes pregnant, I will bring my wife to the Upazila Health Complex for delivery.

One adolescent girl participant of a GD mentioned that:

Today's message was clear and easy to understand. We have seen a number of pictures of different complications, and those who have understood from this meeting will never make the mistake again in our village. At least I am confident that I will follow the messages in my life.

\section{During a FGD, one FPI said:}

We have found pregnant mothers come to join the SA session when they understand what topics are to be discussed. They mentioned that they will follow the instructions and if any maternal complications occur, immediately go to a nearby facility.

Another elderly woman in a GD stated:

We learnt what we should do in the pregnancy period and during delivery and when we have to go to the facility. We should be careful about the neonates also.

One HI reported:

I found that many of the households mentioned that in the future they would arrange a van rickshaw (nonmotorised vehicle) for the pregnant mothers of village to transport them to the facility at the time of delivery.

Participant (an adolescent girl) said during a GD that, after participating in the SA she has been made aware of the negative aspects of child marriage and the importance of antenatal care, postnatal care and care at the 
health facility. Health and Family Planning Department managers mentioned that $\mathrm{SA}$ is an excellent tool for community action. Knowing the events that occurred, the community immediately responded and prepared their own strategy. For rural villagers, SA was an eye opener for the general community.

One UHFPO mentioned during interview:

It's the place for decision making for the community collectively. In the presence of local elites, it becomes a place of social commitment to rectify the errors within society about maternal and neonatal complications and deliveries.

\section{Another UFPO mentioned:}

During my monitoring visit to observe a Social Autopsy, it had a positive effect in the society-community people received the message strongly because I am leading family planning department.

\section{Strengths, challenges and lessons learnt}

Community participation and action on a maternal or neonatal death event was found to be a key strength in the SA process. It was understood that this innovative, socially interactive approach to death with the community was effective for preparing corrective action plans. A community remedial action plan was devised at the time of an SA session, and individuals participating in the meeting showed commitment to taking action in the future. The BCC materials used in SA are practical and realistic, and the community showed their interest and listened throughout the session. Moreover, the platform brought different social groups together including adolescents, seniors, reproductive women, pregnant mothers and male decision-makers. The presence of local elites or leaders of local government gave SA even more legitimacy. Local government leaders participating in SA sessions developed a sense of ownership and commitment to take responsibility for their respective community. In the community, SA acts as an effective response to death, with a main key strength being community decision-making for future death prevention.

However, there remain challenges in involving more male participants, since in the majority of cases they are the decision makers. Continuous support is required from health workers since their role is crucial to organising the sessions; therefore, refresher training is required to improve and retain health workers' communication skills.

During a GD, one of the elected local government leaders said:

I'm a member of Union Parisad. We were not careful, we didn't know about the complications of pregnant mothers and children. Our health worker discussed wonderfully with the villagers. The mothers and their family have now become aware of pregnancy-related complications. I will also take responsibility from Union Parisad to look after my community from now onwards.

During a discussion with a UHFPO, it was mentioned:

SA is accepted by the community and we have found better outputs from them. Continuous sensitisation will help to reduce maternal and neonatal deaths in the future.

During an interview, one of the SA participants said:

We never knew about maternal and neonatal complications before. We did not have ideas on birth planning as well. This meeting opened our eyes, we can now visualise where we made mistakes, but we will not make the same mistakes again.

One HI said:

We are now experiencing that many of the pregnant mothers are coming to the community clinic and visiting the Upazila health complex to receive antenatal caremany of them already delivered a baby at the facility. Social Autopsy helped these mothers to understand the reality and what really they need to do.

One of the UHFPOs who had participated in some of the SA sessions during his monitoring visit said:

Community ownership and proper understanding is the key outcome of a Social Autopsy. This platform creates an opportunity to learn from mistakes already made and provide scope to rectify them by knowing the proper message. Moreover, the community decides in the meeting on what they will do in the future.

Another health worker said:

In a few cases during the holding of an SA, the audience raised blame against the health system or health care providers. We minimised that tactfully and concentrated our talk more about complications.

While one of FPI said:

We faced challenges in managing time, because sometimes it took more time than usual. The gathering of neighbours also took time and, moreover, we needed to stay until the discussion ended, so almost half of the day was spent doing SA in many cases. Moreover, the distance to visit the household sometimes took more time.

\section{DISCUSSION}

This study revealed that community SA helped to identify the social factors and errors behind maternal or newborn complications that cause deaths. The field-level government health and family planning staff facilitated each of the SA session and they contributed towards the community in a better way. It also showed that the community could prepare itself by making decisions and 
commit to prevent such deaths without apportioning any blame. SAs also acted as a form of debriefing for community members to discuss about what had happened. Engagement of community leaders, elites and seniors created a conducive environment to improve the overall health-seeking behaviour in rural Bangladeshi society. SAs have created a positive environment of trust to improve the health-seeking behaviour at the community level especially for maternal and neonatal health. ${ }^{28}$

In this study, SA was used as a social intervention after the verbal autopsy on maternal and neonatal deaths had been undertaken in the community. SA was well accepted by the community and health workers. A number of societal factors and barriers were identified, including delays that contributed to the death of mothers and newborns. A study from Kenya reported that SA in maternal death was a powerful tool for determining the contextual factors related to death. ${ }^{29} \mathrm{We}$ found that SA helped to sensitise the community to take appropriate, corrective measures and created a platform for the demonstration of commitment by rural people for future death prevention and reduction. SAs have been reported to deliver large-scale information, determinants of deaths and an increase in awareness of maternal and child death as preventable issues and empower communities. ${ }^{30}$ SA has also been used as a tool to determine mortality in children under 5 years of age and explore common barriers to healthcare, risky behaviours and missed health and safety opportunities. ${ }^{31}$

We found that a major strength of conducting SAs was community participation in the process in the presence of government health workers. This format helped to highlight important issues and seek solutions without blaming anyone, while at the same time maintaining confidentiality. The community responses thus help to reduce future incidents. The maternal death surveillance and response developed by the WHO also found that death review findings translate into health manager responses and reduce maternal deaths. ${ }^{32}$ The sustainable development goal 3 addressed maternal mortality to 70/100 000 live births. ${ }^{33}$ That means focused intervention such as SA has the potential to intervene in the community, which can help to reduce the burden of deaths by 2030. Maternal and Perinatal Death Inquiry and Response (MAPEDIR) initiatives in India seek to identify obstacles in the existing social system, including healthcare services, and provide a mechanism by which factors relating to maternal death can be changed while emphasising the non-blaming approach. ${ }^{34}$ Similar findings were also reported in another study where exclusive discussion of maternal death cases were conducted by way of meetings with health providers, policymakers and community members to improve the quality of care and services. ${ }^{35}$

SA is unstructured and there are currently no validated instruments to explore social causes and societal responses on taking corrective measures following maternal or neonatal deaths. In this study, SA used government-approved community BCC materials for transfer of knowledge. The whole interaction followed a guideline, which guided the health worker to ensure focused discussion.

SA at district and below level is a new experience and know its effect in maternal and neonatal health. Health workers at different district levels are the key players in implementing SA. Therefore we have interviewed health managers at district and subdistrict level to know their experience on conducting SA rather than at national level. However, similar SA approaches have been practiced in Bangladesh to reduce road traffic injuries. ${ }^{36} \mathrm{SA}$ has the capacity to focus on modifiable community factors to support changes in practice and behaviour in families. It also helps to build awareness and strengthen the community to act on future preventative measures. ${ }^{19}$

\section{CONCLUSIONS}

Here we explored SA as a tool for developing community interactions regarding specific deaths while simultaneously sensitising and stimulating people to explore existing social barriers. These interactive meetings explored solutions to which the community could commit. A community response through knowledge of social errors is a positive step that can accelerate community participation in future death reduction and prevention. Preventing maternal and neonatal deaths is challenging, especially ensuring the availability of high-impact interventions for every mother and newborn. ${ }^{37}$ The effect of the SA in this context is strategic and can be used as a simple tool in the community to help individuals respond to death and implement corrective measures for the future. In this way, SA has the potential scope to support the reduction of maternal and neonatal deaths in low income countries such as Bangladesh.

Acknowledgements The authors thank the Directorate General of Health Services (DGHS) and Directorate General of Family Planning (DGFP), Ministry of Health and Family Welfare (MOHFW) of the Government of the People's Republic of Bangladesh for implementing Maternal and Neonatal Death Review under a joint GoB-UN Maternal Neonatal Health initiative. They are also grateful to UNICEF, Bangladesh for providing technical and financial support via Canadian CIDA (DFATD) and the Department for International Development (DFID) and European Commission (EC) to initiate the pilot study.

Contributors $A B, F R$ and $A H$ developed the concept and design research methodology. $A B$ and $A H$ were involved in implementation of the research. $A B, K D$ and $C E$ were involved in data analysis and interpretation. $A B, F R, C E$, $A H$ and $K D$ drafted the manuscript. $K D$ had critically reviewed the manuscript. All authors read and approved final manuscript.

Funding UNICEF, Bangladesh via Canadian CIDA (DFATD) and the Department for International Development (DFID) and European Commission (EC) to initiate the pilot study.

\section{Competing interests None declared.}

Ethics approval The Institutional Ethical Review Committee of the Centre of Injury Prevention and Research, Bangladesh reviewed and approved the research study.

Provenance and peer review Not commissioned; externally peer reviewed.

Data sharing statement Qualitative information is stored at the department of reproductive and child health unit of CIPRB. Data can be available upon 
prior permission from the organization and corresponding author can be contacted for further communication.

Open Access This is an Open Access article distributed in accordance with the Creative Commons Attribution Non Commercial (CC BY-NC 4.0) license, which permits others to distribute, remix, adapt, build upon this work noncommercially, and license their derivative works on different terms, provided the original work is properly cited and the use is non-commercial. See: http:// creativecommons.org/licenses/by-nc/4.0/

\section{REFERENCES}

1. Chowdhury AM, Bhuiya A, Chowdhury ME, et al. The Bangladesh paradox: exceptional health achievement despite economic poverty. Lancet 2013;382:1734-45.

2. Khanam RA, Khan M, Halim MA, et al. Facility and community based maternal death review in Bangladesh. Bangladesh $\mathrm{J}$ Obs Gynaecol 2009;24:18-21.

3. UNICEF. Maternal and Neonatal Health in Bangladesh. 2009. http:// www.unicef.org/bangladesh/Maternal_and_Neonatal_Health.pdf

4. WHO. Trends in Maternal Mortality: 1990 to 2013 Executive Summary. 2014. http://apps.who.int/iris/bitstream/10665/112697/1/ WHO_RHR_14.13_eng.pdf?ua=1

5. Ministry of Health and Family Welfare. Health Bulletin 2014. Mohakhali: Management Information System Directorate General of Health Services, 2014.

6. Halim A, Utz B, Biswas A, et al. Cause of and contributing factors to maternal deaths; a cross-sectional study using verbal autopsy in four districts in Bangladesh. Br J Obs Gynae 2014;121:86-94.

7. Say L, Raine R. A systematic review of inequalities in the use of maternal health care in developing countries. Bull World Heal Organ 2007;85:812-19.

8. Pearson L, deBernis L, Shoo R. Maternal death review in Africa. Int J Gynaecol Obstet 2009;106:89-94.

9. Høj L, Aaby P. Maternal mortality in Guinea-Bissau: the use of verbal autopsy in a multi-ethnic. Int J Epidemiol 2000;28:70-6.

10. De Brouwere V, Lewis G, Filippi V, et al. Maternal death reviews. Lancet 2013;381:1718-19.

11. Hofman JJ, Sibande Ndemera M. Review of community based maternal deaths in Mangochi district. Malawi Med J 2005;17:81-4.

12. Kalter HD, Mohan $P$, Mishra A, et al. Maternal death inquiry and response in India - the impact of contextual factors on defining an optimal model to help meet critical maternal health policy objectives. Health Res Policy Syst 2011;9:41.

13. Walraven G, Telfer M, Rowley J, et al. Maternal mortality in rural Gambia: levels, causes and contributing factors. Bull World Health Organ 2000;78:603-13.

14. Maternal Deaths in the Maldives. 2011:1-13 (cited 25 Dec 2014). http://www.searo.who.int/maldives/documents/Maternal_Deaths_in the_Maldives_2009-2011_-_short_report_edit_3.pdf

15. Khatun F, Rasheed S, Moran AC, et al. Causes of neonatal and maternal deaths in Dhaka slums: implications for service delivery. BMC Public Health 2012;12:84.

16. lyengar $\mathrm{K}$, lyengar SD, Suhalka V, et al. Pregnancy-related deaths in Rural Rajasthan, India: exploring causes, context, and care-seeking through verbal autopsy. J Health Popul Nutr 2009;27:293-302.

17. Hussain $F$, Bhuiyan $A B$, Haque $Y A$, et al. Verbal autopsy for maternal death. Bangladesh Med Res Counc Bull 2002;28:45-53.

18. Jafarey SN, Rizvi T, Koblinsky M, et al. Verbal autopsy of maternal deaths in two districts of Pakistan-filling information gaps. J Health Popul Nutr 2009;27:170-83.
19. Waiswa P, Kalter HD, Jakob R, et al. Increased use of Social Autopsy is needed to improve maternal, neonatal and child health programmes in low-income countries. Bull World Health Organ 2012;90:403-403A

20. Biswas A, Rahman F, Eriksson C, et al. Community notification of maternal, neonatal deaths and still births in Maternal and Neonatal Death Review (MNDR) system: experiences in Bangladesh. Health 2014;6:2218-26.

21. Biswas A, Rahman F, Halim A, et al. Maternal and Neonatal Death Review (MNDR): a useful approach to identifying appropriate and effective maternal and neonatal health initiatives in Bangladesh. Health 2014;6:1669-79.

22. Biswas A, Rahman F, Halim A, et al. Experiences of community verbal autopsy in maternal and newborn health of Bangladesh. HealthMED 2015;9:329-38.

23. Islam F. Quality improvement system for maternal and newborn health care services at district and sub-district hospitals in Bangladesh [Doctoral thesis]. Orebro University, 2016.

24. Biswas A. Maternal and neonatal death review system to improve maternal and neonatal health care services in Bangladesh. Orebro University, 2015.

25. Silverman D. Doing qualitative research: a practice handbook. London: SAGE publications, 2000.

26. Boyatzis RE. Transforming qualitative information: thematic analysis and code development. Thousand Oaks, CA: SAGE publications, 1998.

27. Graneheim UH, Lundman B. Qualitative content analysis in nursing research: concepts, procedures and measures to achieve trustworthiness. Nurse Educ Today 2004;24:105-12.

28. Biswas A. Maternal and Perinatal Death Review (MPDR) experiences in Bangladesh. World Health Organization. 2015 (cited 27 October 2015). http://www.who.int/maternal_child_adolescent/ epidemiology/maternal-death-surveillance/case-studies/ bangladesh-study/en/

29. Njue RK, Warren C, Obare F, et al. O500 Social Autopsy for maternal deaths: investigating the causes of and contributors to maternal mortality in Kenya. Int J Gynecol Obstet 2012;119:S438.

30. Kalter HD, Salgado R, Babille M, et al. Social Autopsy for materna and child deaths: a comprehensive literature review to examine the concept and the development of the method. Popul Health Metr 2011;9:45.

31. Källander K, Kadobera D, Williams TN, et al. Social Autopsy: INDEPTH Network experiences of utility, process, practices, and challenges in investigating causes and contributors to mortality. Popul Health Metr 2011;9:44.

32. World Health Organization. Maternal death surveillance and response: technical guidance, information for action to prevent maternal death. Bull World Health 2013:1-128. http://www.scielosp. org/scielo.php?pid=S0042-96862011001100003\&script=sci_ arttext\&ting $=\mathrm{pt}$

33. United Nations. Sustainable Developmental Goal [Internet] (cited on November 2015). 2015:1-7. http://sustainabledevelopment.un.org

34. Dikid T, Gupta M, Kaur M, et al. Maternal and perinatal death inquiry and response project implementation review in India. J Obstet Gynaecol India 2013;63:101-7.

35. Supratikto $\mathrm{G}$, Wirth ME, Achadi E, et al. A district-based audit of the causes and circumstances of maternal deaths in South Kalimantan, Indonesia. Bull World Health Organ 2002;80:228-34.

36. Baset M, Towner E, Mashreky S, et al. Social Autopsy: a community based intervention in preventing road traffic injuries-experience from Bangladesh. Inj Prev 2012;18:A205-A205.

37. Bryce J, Black RE, Victora CG. Millennium Development Goals 4 and 5: progress and challenges. BMC Med 2013;11:225. 